\title{
Analysis of Streamflow Response to Changing Climate Conditions Using SWAT Model
}

\author{
Han Thi Oo ${ }^{\text {a }}$, Win Win Zin ${ }^{\text {a }}$, Cho Cho Thin Kyi ${ }^{{ }^{*}}$ \\ ${ }^{a}$ Department of Civil Engineering, Yangon Technological University, Yangon and 11181, Myanmar.
}

Received 06 November 2019; Accepted 12 January 2020

\begin{abstract}
The understanding of climate change is curial for the security of hydrologic conditions of river basins and it is very important to study the climate change impacts on streamflow by analyzing the different climate scenarios with the help of the hydrological models. The main purpose of this study is to project the future climate impact on streamflow by using the SWAT model. The multi-model projections indicated that Upper Ayeyarwady River Basin is likely to become hotter in dry season under low rainfall intensity with increasing temperature and likely to become wetter but warmer in both rainy and winter season because of high rainfall intensity with increased temperature in future. The impact of climate change scenarios is predicted to decrease the annual streamflow by about 0.30 to $1.92 \%$ under RCP2.6, 5.59 to $7.29 \%$ under RCP4.5 and 10.43 to $11.92 \%$ under RCP8.5. Based on the change in high and low flow percentage with respect to the baseline period, the difference between high and low flow variation range will increase year by year based on future scenarios. Therefore, it can be concluded that it may occur more low flow in the dry season which leads to increase in water scarcity and drought and more high flow in the wet season which can cause flooding, water insecurity, stress, and other water-related disasters.
\end{abstract}

Keywords: Climate Change; SWAT Model; Streamflow; High and Low Flow.

\section{Introduction}

The assessment of climate change impact on streamflow is one of the most interesting issues in hydrological research [1]. Changes in air temperature and precipitation cause a major impact on the hydrologic cycle directly and indirectly and moreover, the water resources [2]. Climate change altering the amount, intensity, form, and timing of precipitation as well as the rate of evapotranspiration also affects hydrological regimes by affecting the volume, peak rate, and timing of river flow [3]. For studying the impact on the regional water resource availability, the estimation of changes in river flow is the most common and is considered for decision-making processes in water-resource management [4].

Myanmar is situated in the tropical climate region with three dominant seasons: the hot season (16 February to May), the wet season (June to September), and the cold season (October to 15 February) [5] and a region that is highly vulnerable to impacts from climate change. There are about 60 rivers in Myanmar [6], the country's largest main river is Ayeyarwaddy and it is an important commercial waterway used for trade and transport. The Ayeyarwaddy River is divided into the upper and lower parts with the river confluence with the Chindwin River [7]. Upper Ayeyarwady river basin is one of the major river basins in Myanmar and consists of Central Dry Zone and the Northem Hilly Region. The central dry zone area is known as the "oil pot" of the country and the economic growth of the country through agricultural development is essential in prenatal economic life. However, current climate change effects such as high temperature,

* Corresponding author: ccthinkyi@gmail.com 
scarce rainfall, etc. are now threatening agricultural crops and farmers' livelihood. So, climatic condition in dry zone region is the key factor for the development of the agriculture and farmers' livelihood [8]. In the northern hilly region, it is already experiencing the problems of flood and heavy rains [9] and this effect may be more severe in the future due to climate change [10]. Therefore, information about the future streamflow related to climate change for this river plays as a fundamental role. It is essential to quantify and understand climate changes in the Upper Ayeyarwady river basin and those likely to occur over the coming century. This is also a starting point that Myanmar's stakeholders can use to plan for more summer monsoon rainfall in agriculture, hydropower, conservation areas, dams, flood management and so on [11].

It is important to understand Information derived from Global Climate Models (GCMs) and general characteristics of GCMs for assessing both past and future likely changes in climate scenarios and for assessing the climate change impact on hydrological analysis [12]. Future climate scenarios were produced based on a statistical relationship between climate variables at one or more GCM grid points with the variable of interest at a particular station [13]. Scenarios are images of how the world is likely to evolve in the future in terms of greenhouse gas [14]. In this study, climate information obtained from Representative Concentration Pathways (RCPs) is used to forecast future hydrological changes. There are so many hydrological models for understanding the impact of climate change on the nature of hydrological flow and for calculation of water discharge more accurately, easily and quickly than the traditional measurement method. Soil and Water Assessment Tool (SWAT) is one of the most popular modelling software for assessing hydrologic impacts. The main objective of this study is to forecast the impact of future climate projections on streamflow of the future period by using the projections of precipitation and temperature based on outputs of selected suitable climate models from downloaded 10 GCMs under RCP Scenarios across the Upper Ayeyarwaddy River Basin. The structure of this article is organized as follows: study area descriptions are presented in Section 1. Methodological framework is described in Section 2 and materials and methods of this study are described in Section 3. Section 4 presents the results and discussions of this study. Finally, conclusion is described in Section 5.

\subsection{Study Area}

In this study, climate change impacts on the water sector highlight the Upper Ayeyarwaddy river basin which is covering about $60 \%$ of the total area of Myanmar and originates at the confluence of the N'Mai Hka and Mali Kha rivers. The Upper Ayeyarwaddy is situated at $20^{\circ} 22^{\prime}$ - $28^{\circ} 50^{\prime}$ north latitude and $94^{\circ} 56^{\prime}-98^{\circ} 42^{\prime}$ ' east longitude [15] and covered by Kachin State, Mandalay Division, the western part of Shan state and Southeastern part of Sagaing Division as shown in Figure 1. The outlet of the whole basin was selected at Sagaing and the watershed area for this Upper Ayeyarwaddy River is $152,264 \mathrm{~km}^{2}$.

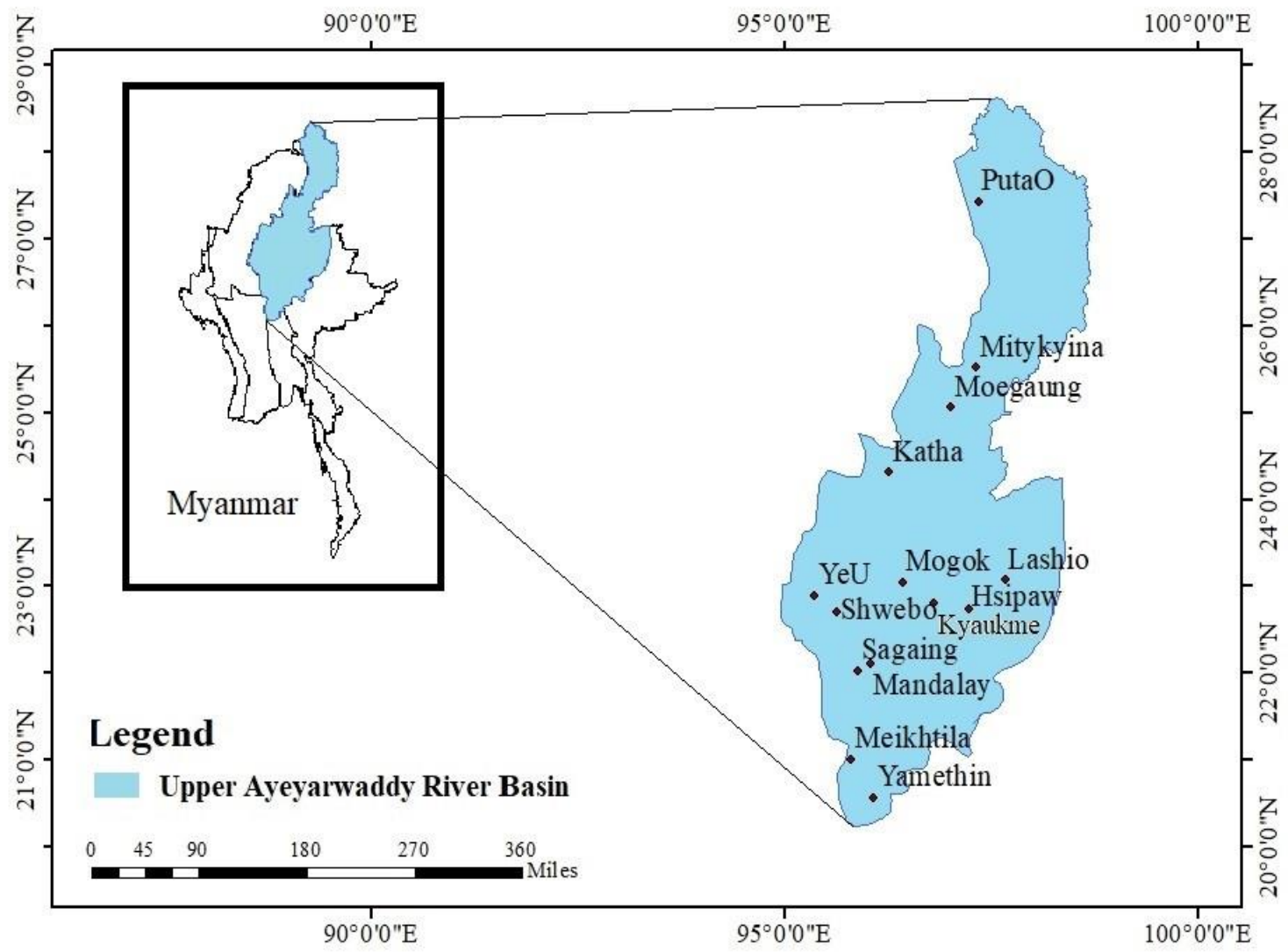

Figure 1. Location of the study area 


\section{Methodological Framework}

The objective of this study has combined two aspects: firstly, assessment of climate change impacts on the climate variables (rainfall and temperature) and secondly, assessment of the response on the river's hydrologic system of climate variables. The Methodological Framework of this study is shown in Figure 2 and involves: (I) spatial and climate data preparation into SWAT format, (ii) model setup, including watershed delineation and Hydrologic Response Units (HRUs), (iii) model calibration and validation, and (iv) assessment of future climate change impacts on streamflow. SWAT model which is ArcGIS extension, ArcSWAT 2012 version was downloaded from the United States Department of Agriculture (USDA) website. SWAT is a partially distributed model and required digital elevation model (DEM), land use and soil map which are basic modeling requirements and daily weather data. Calibration and Validation were performed using the SWAT CUP program. At this stage, several hydrological model parameters were adjusted for achieving the best fit between the simulated and measured flow at the monitoring station. Finally, climate change impact on future streamflow is projected by using the SWAT model based on meteorological changes under climate change projection.

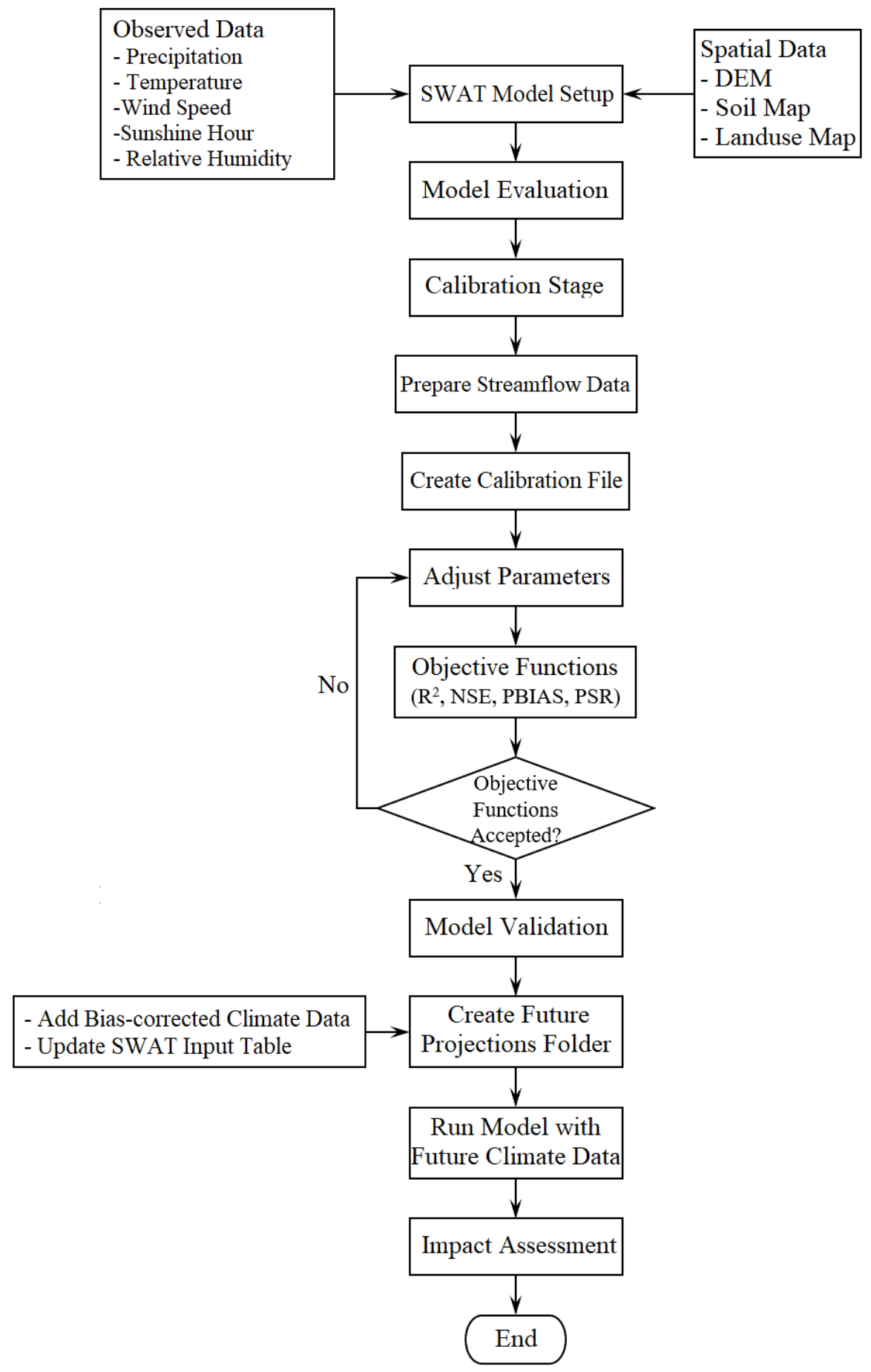

Figure 2. Methodology framework for the assessment of climate change impacts on future flows of the Upper Ayeyarwady River Basin 


\section{Materials and Method}

\subsection{Global Climate Models (GCMs)}

GCMs are the primary tools that provide reasonably accurate global, hemispheric, and continental-scale climate information and are used to understand present and future climate scenarios under increased greenhouse gas concentrations [13]. The CMIP5 is a newly developed data archive and contains a great number of model output enhance the understanding of climate processes and their effects. These data will provide a basis of the Intergovernmental Panel on Climate Change (IPCC) Fifth Assessment Report (AR5). GCMs are models to generate a description of the state of the atmosphere and produce most of the meteorological variables, such as wind speed, relative humidity, rainfall, surface air temperature and solar radiation [16].

\subsection{Representative Concentration Pathways}

RCP based projections were used in the most recent IPCC Fifth Assessment Report (AR5). According to the change in radiative forcing by 2100 , there are four RCPs. RCP 2.6 is representative of scenarios that lead to very low greenhouse gas concentration levels [17]. RCP 4.5 and RCP 6 are stabilization scenarios that lead to intermediate greenhouse gas concentration levels. RCP 8.5 is representative of scenarios that lead to high greenhouse gas concentration levels [18]. The future projections are based on the future radiative forcing of the atmosphere. Three of the RCPs: the low emission scenario (RCP2.6), the mitigation scenario (RCP4.5) and the high emission scenario (RCP8.5) which is characterized by increasing greenhouse gas emissions are used in this study.

\subsection{Meteorological and Hydrological Data Collection}

Weather data such as daily precipitation and temperature data of all fourteen stations within Upper Ayeyarwaddy River Basin are used in this study form 1981 to 2015 and these are acquired form the Department of Meteorology and Hydrology (DMH). Other data such as wind speed, solar radiation and relative humidity from the period 1981 to 2013 are collected from Global Weather Data for SWAT Website. The data availability period of the Sagaing hydrological station which is the outlet station of the Upper Ayeyarwaddy River Basin is 1991 to 2015.

\subsection{Soil and Water Assessment Tool (SWAT) Model}

Hydrological models are becoming more and more widespread, mainly due to their capacity to simulate the impact of environmental changes on water resources [19]. The Soil and Water Assessment Tool abbreviated as SWAT is a basin-scale model that was developed by the United States Department of Agriculture (USDA) - Agriculture Research Service (ARS) [20]. The SWAT model simulates hydrology as a two-component system, composed of land and channel hydrology. The land portion of the hydrologic cycle is based on a water mass balance. Soil water content is computed using the water balance equation [21]:

$\mathrm{SW}_{\mathrm{t}}=\mathrm{SW}+\sum_{\mathrm{i}=1}^{\mathrm{t}}\left(\mathrm{R}_{\mathrm{i}}-\mathrm{Q}_{\mathrm{i}}-\mathrm{ET}_{\mathrm{i}}-\mathrm{P}_{\mathrm{i}}-\mathrm{QR}_{\mathrm{i}}\right)$

Where, SW is the soil water content; $\mathrm{i}$ is time in days for the simulation period $\mathrm{t}$; R is the daily precipitation; and Q, ET, $\mathrm{P}$ and $\mathrm{QR}$ respectively, are runoff, evapotranspiration, percolation and return flow.

Other than the topographic, soil and LULC data, SWAT requires spatially explicit datasets of climatic data at daily/sub-daily time steps. Major input data for SWAT include DEM, LULC, soil properties, and daily weather data (precipitation, maximum and minimum air temperature, relative humidity, wind speed and solar radiation) [22].

\subsection{SWAT - CUP}

SWAT-CUP is a computer program that was developed for SWAT models. SWAT-CUP was employed for model calibration, validation, and sensitivity analysis by using the observed runoff data. The program links four calibration methods such as Generalized Likelihood Uncertainty Estimation (GLUE), Sequential Uncertainty Fitting Procedure Version 2 (SUFI2), Markov Chain Monte Carlo (MCMC) and Parameter Solution (ParaSol) [23]. SUFI2 method was chosen because it is the most suitable way to find the SWAT uncertainty under the condition that the parameter range was specified. Sequential Uncertainty Fitting Algorithm (SUFI-2) is very advantageous since it combines optimization with uncertainty analysis and can handle large number of parameter to achieve good prediction uncertainty ranges for the period of 6 years (2002 to 2007). Responded to parameter set more sensitive than any others [23, 24].

\subsection{Model Performance Evaluation Procedure}

There are many kinds of error parameters which are widely used for testing and accuracy assessment of the SWAT model; such as Nash-Sutcliffe coefficient of efficiency (NSE), percent bias (PBIAS), coefficient of determination ( $\mathrm{R}^{2}$ ) and RSR (ratio of the root mean square error to the standard deviation of measured data). These parameters indicate the 
goodness of fit of the observed value with the simulated value. The model calibration was aimed to achieve a satisfactory model efficiency of NSE $\geq 0.5$, PBIAS $\leq \pm 25 \%$, and RSR $\leq 0.7$.

The determination coefficient, $\mathrm{R}^{2}$ is used to determine the agreement between the simulated and observed flow data. Model prediction evaluation was categorized as satisfactory if $\mathrm{R}^{2}$ is greater than 0.6 [25].

\section{Results and Discussion}

\subsection{Selection of Suitable Climate Models and Scenarios}

Ten global climate models such as CanESM2, CCSM4, CMCC-CMS, GFDL-CM3, GFDL-ESM2G, MRIOC ESM, MIROC ESM CHEM, MPI ESM LR, MPI ESM MR, MRI- CGCM 3 for the $5^{\text {th }}$ Coupled Model Intercomparison Project (CMIP5) are used to consider to climate projections.

Here, the multi-GCMs approach is applied rather than using single GCM because different GCMs have different grid-sizes and their coverage area. $\mathrm{R}^{2}$ and RMSE (root mean square error) parameters are used for the performance of the bias correction method in model selection. GCM with higher agreement on performance indicators is selected. Suitable climate models for precipitation and temperature for selected stations within the basin are shown in Table 1 .

Table 1. Lists of Suitable Climate Models [26]

\begin{tabular}{cccc}
\hline Stations & Maximum Temperature & Minimum Temperature & Rainfall \\
\hline Hsipaw & GFDL CM3 & MRI CGCM3 & CanESM2 \\
Katha & GFDL CM3 & MRI CGCM3 & CCSM4 \\
Kyaukme & MPI ESMMR & MRI CGCM3 & CanESM2 \\
Lashio & MPI ESMMR & MRI CGCM3 & CanESM2 \\
Mandalay & MPI ESMMR & MRI CGCM3 & CanESM2 \\
Meikhtila & GFDL CM3 & MRI CGCM3 & MIROC-ESM-CHEM \\
Moegaung & GFDL CM3 & MPI ESMMR & CCSM4 \\
Moegok & MRI CGCM3 & MRI CGCM3 & CanESM2 \\
Myitkyina & MRI CGCM3 & MRI CGCM3 & GFDL CM3 \\
PutaO & MRI CGCM3 & MPI ESMMR & GFDL-ESM2G \\
Sagaing & GFDL CM3 & MRI CGCM3 & CanESM2 \\
Shwebo & MPI ESMMR & MRI CGCM3 & CanESM2 \\
Yamethin & GFDL CM3 & MRI CGCM3 & CanESM2 \\
YeU & MPI ESMMR & MRI CGCM3 & CanESM2 \\
\hline
\end{tabular}

\subsection{Projected Precipitation}

Future climate projection baselines (2021-2095) were compared to the meteorological data (1991-2015). Precipitation projections are performed under three horizons: near future for 2021-2045, future for 2046-2070, far future for 2071-2095. Projections of precipitation under RCP2.6, RCP4.5, and RCP8.5 are shown in the following Table 2. This table shows the values of average seasonal changes in precipitation as a fraction of the base period corresponding to scenarios. The seasonal climate in Upper Ayeyarwaddy River Basin is classified into three seasons such as summer from 16 Feb to 31 May, Rainy (Monsoon) from 1 June to 30 Sept and winter from 1 Oct to 15 Feb. RCP2.6 shows an increase in basin average annual precipitation by $20.2,25.7$, and $22.1 \%$ respectively for the near future, future, and far future. RCP 8.5 has a slightly higher increase rate of $27.1,18.5$, and $29.1 \%$ for the same periods. The highest increase of $29.1 \%$ and the lowest increase of $18.7 \%$ will be obtained respectively under RCP8.5 and RCP4.5 in the far future. According to the average seasonal changes, there is a clear estimation in predicted future precipitation amounts of RCP 2.6, RCP4.5 and RCP8.5 receiving reduced rainfall for all future periods in summer season and increased rainfall in rainy and winter season. But, seasonal changes in winter are predicted to become double in the future and it can be said that changes in future precipitation for the winter season are much higher than that of changes in the rainy season. 
Table 2. Average Changes in Future Precipitation

\begin{tabular}{|c|c|c|c|}
\hline \multirow{2}{*}{ Future Period } & \multicolumn{3}{|c|}{ Average Seasonal and Annual Changes in Precipitation as a Fraction of Base Period Corresponding to Scenarios } \\
\hline & RCP2.6 & RCP4.5 & RCP8.5 \\
\hline & \multicolumn{3}{|c|}{ Rainy Seasonal Changes } \\
\hline Near Future & $1.30(30.5 \%)$ & $1.24(24.5 \%)$ & $1.26(26.1 \%)$ \\
\hline Future & $1.29(29.3 \%)$ & $1.15(19.9 \%)$ & $1.26(26.1 \%)$ \\
\hline \multirow[t]{2}{*}{ Far Future } & $1.20(20.5 \%)$ & $1.16(15.7 \%)$ & $1.27(27.2 \%)$ \\
\hline & \multicolumn{3}{|c|}{ Summer Seasonal Changes } \\
\hline Near Future & $0.59(-40.3 \%)$ & $0.86(-14.2 \%)$ & $0.61(-38.7 \%)$ \\
\hline Future & $0.72(-28.1 \%)$ & $0.95(-4.6 \%)$ & $0.69(-30.8 \%)$ \\
\hline \multirow[t]{2}{*}{ Far Future } & $0.82(-18.2 \%)$ & $1.10(9.8 \%)$ & $0.82(-18.0 \%)$ \\
\hline & \multicolumn{3}{|c|}{ Winter Seasonal Changes } \\
\hline Near Future & $2.17(116.9 \%)$ & $1.81(80.8 \%)$ & $1.78(78.2 \%)$ \\
\hline Future & $1.77(76.9 \%)$ & $1.66(66.6 \%)$ & $1.58(58.7 \%)$ \\
\hline \multirow[t]{2}{*}{ Far Future } & $1.88(88.3 \%)$ & $1.36(36.3 \%)$ & $1.38(38.2 \%)$ \\
\hline & \multicolumn{3}{|c|}{ Average Annual Changes } \\
\hline Near Future & $1.20(20.2 \%)$ & $1.30(29.7 \%)$ & $1.27(27.1 \%)$ \\
\hline Future & $1.26(25.7 \%)$ & $1.28(28.5 \%)$ & $1.28(28.5 \%)$ \\
\hline Far Future & $1.22(22.1 \%)$ & $1.19(18.7 \%)$ & $1.29(29.1 \%)$ \\
\hline
\end{tabular}

\subsection{Projected Temperature}

The future projection of average temperature changes on fourteen stations under climate scenarios, which are RCP2.6, RCP4.5 and RCP8.5, are analysed in there periods, near future for 2021-2045, future for 2046-2070, far future for 20712095. According to the future seasonal temperature changes, both maximum and minimum temperature is projected to increase in all scenarios for three future periods and shown in Table 3 and Table 4 . However, the slight increment is occurred under RCP2.6 and ranged from $0.19^{\circ} \mathrm{C}$ to $1.57^{\circ} \mathrm{C}$ for maximum seasonal temperature. Under $\mathrm{RCP} 4.5$, maximum seasonal temperature changes increased with the range from $0.53^{\circ} \mathrm{C}$ to $2.28^{\circ} \mathrm{C}$ and the highest increment occurs between $0.55^{\circ} \mathrm{C}$ to $3.76^{\circ} \mathrm{C}$ under RCP8.5. However, the slight increment is occurred under RCP2.6 and ranged from $0.19^{\circ} \mathrm{C}$ to $1.57^{\circ} \mathrm{C}$ for maximum seasonal temperature. Under RCP4.5, maximum seasonal temperature changes increased with the range from $0.53^{\circ} \mathrm{C}$ to $2.28^{\circ} \mathrm{C}$ and the highest increment has occurred between $0.55^{\circ} \mathrm{C}$ to $3.76^{\circ} \mathrm{C}$ under RCP8.5. The seasonal increases in the average minimum temperature range from $0.78^{\circ} \mathrm{C}$ to $1.48^{\circ} \mathrm{C}$ under $\mathrm{RCP} 2.6$, $0.98^{\circ} \mathrm{C}$ to $2.25^{\circ} \mathrm{C}$ under RCP 4.5 and $1.12^{\circ} \mathrm{C}$ to $3.92^{\circ} \mathrm{C}$ under RCP8.5.

Table 3. Average Seasonal and Annual Changes in Future Maximum Temperature

\begin{tabular}{|c|c|c|c|}
\hline \multirow{3}{*}{ Future Period } & \multicolumn{3}{|c|}{ Average Maximum Temperature Changes Based on Base Period Corresponding to Scenario $\left({ }^{\circ} \mathrm{C}\right)$} \\
\hline & RCP2.6 & RCP4.5 & RCP8.5 \\
\hline & \multicolumn{3}{|c|}{ Rainy Seasonal Changes } \\
\hline Near Future & 0.84 & 0.69 & 0.88 \\
\hline Future & 0.93 & 1.4 & 2 \\
\hline \multirow[t]{2}{*}{ Far Future } & 1.09 & 1.67 & 3.17 \\
\hline & \multicolumn{3}{|c|}{ Summer Seasonal Changes } \\
\hline Near Future & 1.25 & 1.08 & 0.96 \\
\hline Future & 1.45 & 1.72 & 2.2 \\
\hline \multirow[t]{2}{*}{ Far Future } & 1.57 & 2.28 & 3.73 \\
\hline & \multicolumn{3}{|c|}{ Winter Seasonal Changes } \\
\hline Near Future & 0.19 & 0.53 & 0.55 \\
\hline Future & 0.5 & 1.37 & 1.94 \\
\hline \multirow[t]{2}{*}{ Far Future } & 0.76 & 1.72 & 3.36 \\
\hline & \multicolumn{3}{|c|}{ Average Annual Changes } \\
\hline Near Future & 0.59 & 0.75 & 0.78 \\
\hline Future & 0.81 & 1.48 & 2.05 \\
\hline Far Future & 1 & 1.88 & 3.41 \\
\hline
\end{tabular}


Table 4. Average Seasonal and Annual Changes in Future Minimum Temperature

\begin{tabular}{cccc}
\hline & \multicolumn{2}{c}{ Average Minimum Temperature Changes Based on Base Period Corresponding to Scenario $\left({ }^{\circ} \mathbf{C}\right)$} \\
\cline { 2 - 4 } Future Period & RCP2.6 & RCP4.5 & RCP8.5 \\
\cline { 2 - 4 } & & Rainy Seasonal Changes & 1.28 \\
Near Future & 1.05 & 1.16 & 2.3 \\
Future & 1.28 & 1.7 & 3.32 \\
Far Future & 1.43 & 2 & 1.21 \\
\hline Near Future & & Summer Seasonal Changes & 2.63 \\
Future & 1.13 & 1.37 & 3.92 \\
Far Future & 1.24 & 1.89 & 1.12 \\
\hline Near Future & 1.48 & 2.25 & 2.3 \\
Future & & Winter Seasonal Changes & 3.17 \\
Far Future & 0.78 & 0.98 & 1.24 \\
\hline & 1 & 1.52 & 2.41 \\
\hline Near Future & 1.26 & 1.96 & 3.66 \\
Future & & Average Annual Changes \\
Far Future & 0.98 & 1.16 & \\
\hline & 1.16 & 1.71 & 2.06 \\
\hline
\end{tabular}

\subsection{Soil and Water Assessment Tool (SWAT) Model Data Requirements and Set-up}

SWAT is a partially distributed model and required digital elevation model (DEM), land use and soil map which are basic modeling requirements and daily weather data. There are many available global sources for DEM data and the 90m resolution DEM derived from SRTM (NASA Shuttle Rader Topographic Mission) is used to set up for the hydrological modeling by SWAT. The DEM in Figure 3 shows that the elevation in the Upper Ayeyarwady river basin ranges from $50 \mathrm{~m}$ in the lower plains to $5711 \mathrm{~m}$ in the upper region. The DEM is an important parameter for SWAT to classified topography, landscape, elevation, and slope and used in Streamflow network construction for modelling simulation. In SWAT, the first process was automatic watershed delineation and it can define the detail of flow direction and accumulation of each and every part of the large watershed which was divided into 23 sub-watersheds. These subbasins were then divided into Hydrologic Response Units (HRUs) to predict runoff separately.

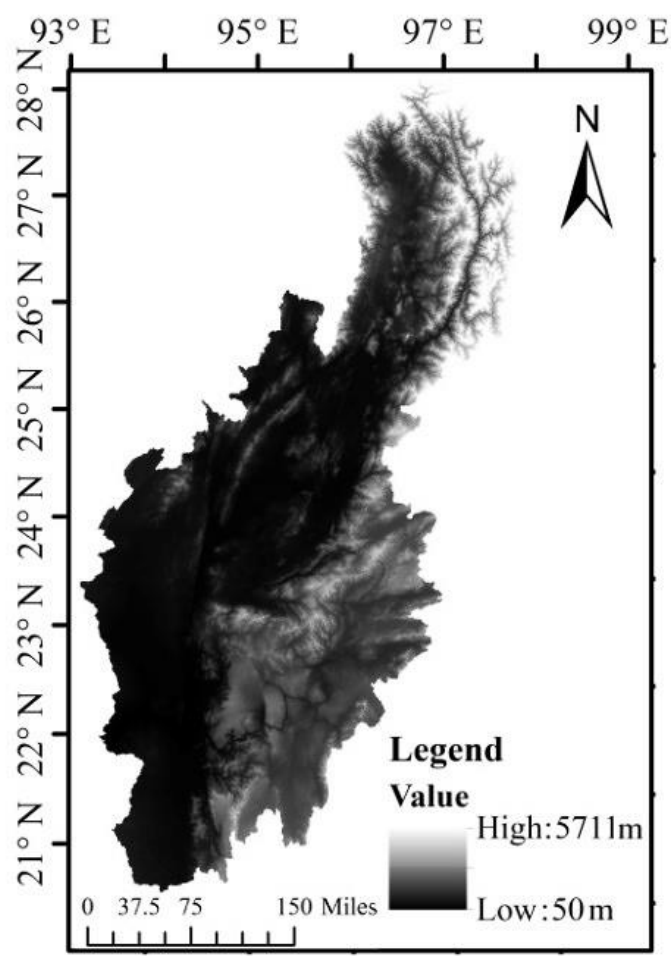

Figure 3. Digital Elevation Map 
For the rainfall-runoff relationship, landcover and soil digital map are used to simulate the model. Land cover in Figure 4 has a 90m grid resolution with a 15 class landcover classification scheme and is obtained from the Servir Mekong Land Cover Portal. Soil dataset with 90m grid resolution is generally classified into 17 classes in Figure 5. For this study, thresholds for defining HRUs to compute a water balance based on snow, soil, shallow aquifer and deep aquifer were set at $20 \%$ for soil and $10 \%$ for land use [27]. Land cover map and soil map were prepared with their lookup tables to join raster data in the SWAT database file. SWAT model requires a soil map and a database table of soil texture for available water content, hydraulic conductivity, bulk density and organic carbon content for different layers of each soil type. The main hydrological processes include infiltration, runoff, evapotranspiration, lateral flow, and percolation [28]. Precipitation, maximum and minimum temperature, relative humidity, sunshine hours and wind speed of 1991 to 2013 were prepared in the text file for each station to compute weather generator parameters for the simulation of hydrological process on the basin. After that, different methods of water balance, surface runoff and reaches are defined.
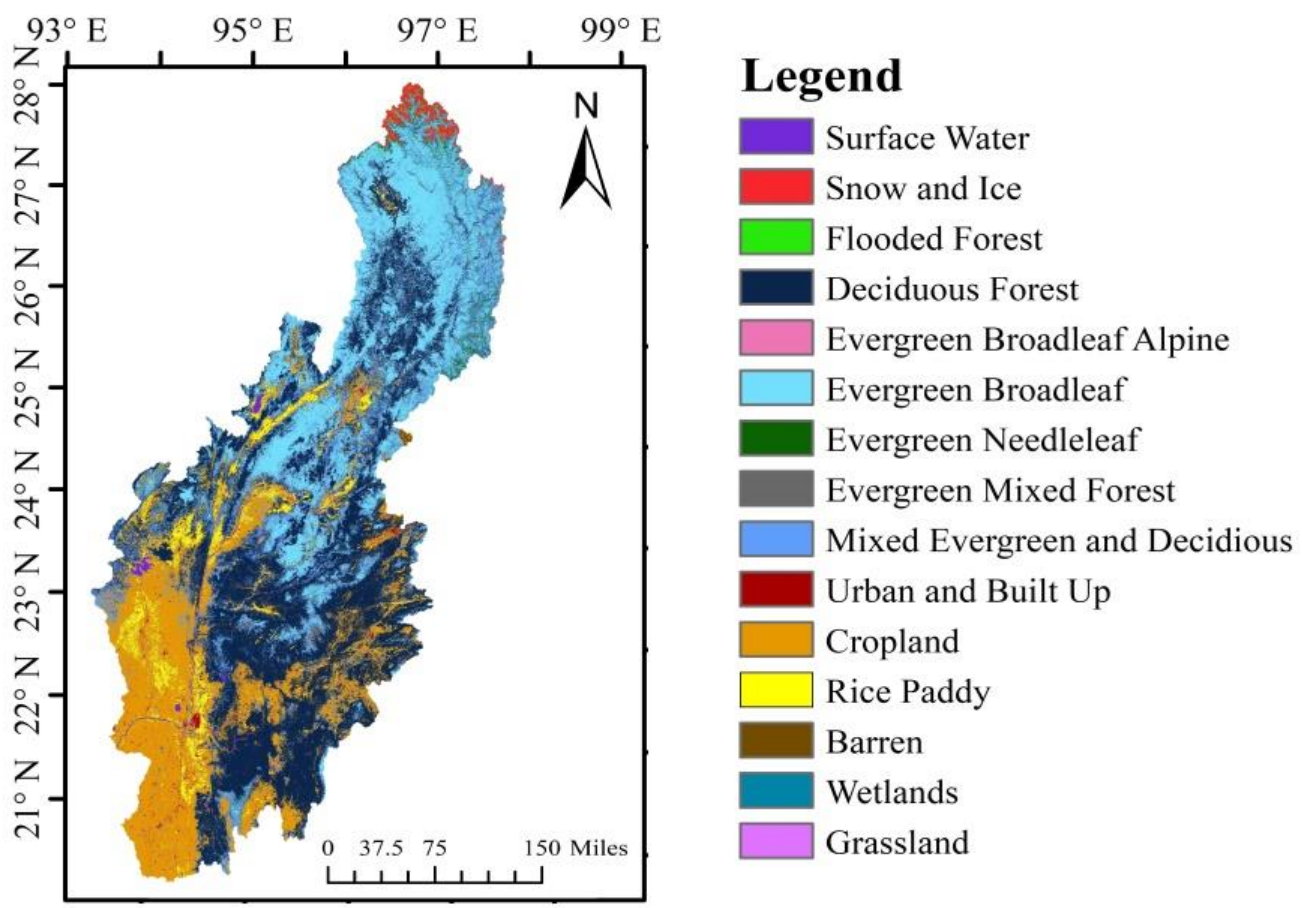

Figure 4. Landcover Classification Map

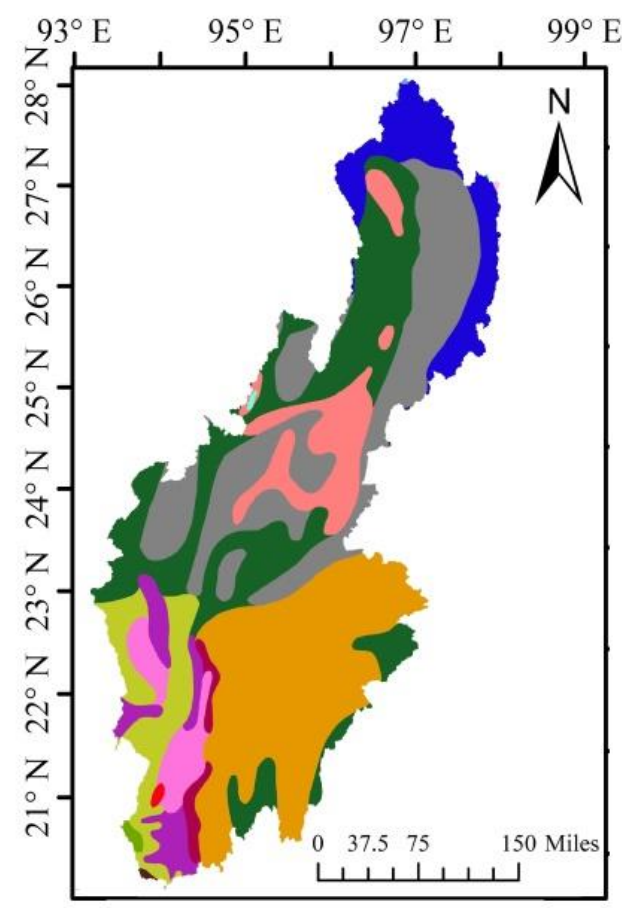

\section{Legend}

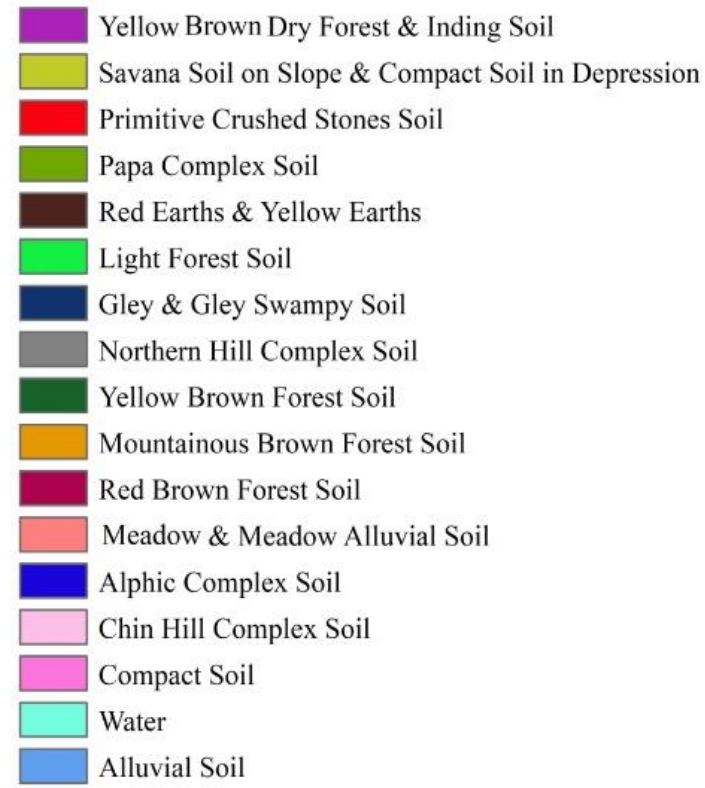

Figure 5. Soil Classification Map 
Surface runoff can be simulated by two methods in the SWAT model: the modified Soil conservation Service Curve Number Method and the Green-Ampt Infiltration Method. In this study, surface runoff was estimated using the SCS Curve Number. Among three methods for estimating potential evapotranspiration: Priestley \& Taylor, the PanmenMonteith and Hargreaves \& Samani, Panmen-Monteith method is used for calculation of evapotranspiration and soil and snow evaporation. Variable Storage routing was used for channel routing [29].

\subsection{Calibration and Validation of Streamflow}

Daily river flow $\left(\mathrm{m}^{3} / \mathrm{sec}\right)$ observed at the Sagaing gauging station which is the outlet of the Upper Ayeyarwady river basin was used for the model calibration and validation analysis. Generally, hydrological models require a "warm-up" period, defined as the time the model will run before starting to generate the actual outputs, in order to eliminate the initial bias. In this study, the period 2000-2001 was used as "warm-up" periods to allow the model to initiate the hydrological parameters. The period of 2002 to 2007 of the streamflow data was used for calibration to estimate the model parameters values and the stability of these parameters were tested in the validation period of 2008 to 2013. Calibration was performed using the SWAT CUP program. Among the four calibration methods, calibration, and validation were conducted using the Sequential Uncertainty Fitting Algorithm (SUFI-2). Several hydrological model parameters were adjusted for achieving the best fit between the simulated and measured flow at the monitoring station. The total of twenty parameters as relating to surface hydrology, groundwater hydrology, snowpack accumulation, snowmelt, and base flow was selected and the lists of initial and fitted parameter range over all the study basins are reported in Table 5. Both calibration and validation on simulated streamflow with observed data were done by using the final parameters ranges.

Table 5. Parameters for Sensitivity Analysis

\begin{tabular}{|c|c|c|c|c|c|}
\hline \multirow{2}{*}{ Parameters } & \multicolumn{2}{|c|}{ Initial Parameter Range (Default) } & \multicolumn{2}{|c|}{ Final Parameter Range } & \multirow{2}{*}{ Fitted Parameter Range } \\
\hline & Min & Max & Min & Max & \\
\hline \multicolumn{6}{|c|}{ Groundwater Parameters } \\
\hline GW_DELAY.gw & 0 & 500 & 250 & 500 & 406.2 \\
\hline ALPHA_BF.gw & 0 & 1 & 0.001 & 0.01 & 0.002 \\
\hline GWQMN.gw & 0 & 5000 & 1500 & 3000 & 1612.5 \\
\hline GW_REVAP.gw & 0.02 & 0.2 & 0.005 & 0.05 & 0.035 \\
\hline REVAPMN.gw & 0 & 500 & 250 & 300 & 283.7 \\
\hline RCHRG_DP.gw & 0 & 1 & 0.07 & 0.7 & 0.49 \\
\hline \multicolumn{6}{|c|}{ Surface Parameters } \\
\hline CN2.mgt & 35 & 98 & -1 & 3.5 & -0.887 \\
\hline SURLAG.bsn & 0.05 & 24 & 0.05 & 6 & 5.85 \\
\hline OV_N.rte & 0.01 & 30 & 15 & 30 & 27.38 \\
\hline CH_N2.rte & -0.01 & 0.3 & 5 & 10 & 7.38 \\
\hline CH_K2.rte & -0.01 & 500 & -0.01 & 10 & 9.75 \\
\hline HRU_SLP.hru & 0 & 1 & 7.5 & 10 & 9.44 \\
\hline SLSUBBSN.hru & 10 & 150 & 145 & 150 & 147.9 \\
\hline \multicolumn{6}{|c|}{ Soil Parameters } \\
\hline SOL_AWC.sol & 0 & 1 & 0.8 & 1 & 0.86 \\
\hline SOL_K.sol & 0 & 2000 & 10 & 20 & 12.75 \\
\hline SOL_BD.sol & 0.9 & 2.5 & 0.9 & 1 & 0.913 \\
\hline ESCO.hru & 0 & 1 & 0.001 & 0.01 & 0.008 \\
\hline EPCO.hru & 0 & 1 & 0.5 & 0.9 & 0.59 \\
\hline \multicolumn{6}{|c|}{ Snow Parameters } \\
\hline SFTMP.bsn & -20 & 20 & -5 & 5 & 3.25 \\
\hline SMTMP.bsn & -20 & 20 & -5 & 5 & 2.75 \\
\hline
\end{tabular}

1) Statistical Approaches for model performance evaluation: For the accuracy of simulated model results, the model calibration has to be done to match modelled streamflow results with observed discharge. Surface runoff was calibrated many times by adjusting the parameters to compare with observed data. In this study, the model performance was checked with Nash-Sutcliffe efficiency (NSE), coefficient of determination $\left(\mathrm{R}^{2}\right)$, percent bias (PBIAS), and ratio of the root mean square error to the standard deviation of measured data (RSR). The calibration process was does until NSE > 
$0.5, \mathrm{R}^{2}>0.5, \mathrm{RSR} \leq 0.7$, PBIAS $<25 \%$. The validation process is also performed to check the calibrated model accuracy. The statistical result of model validation indicates that the model can be used with calibrated basin parameters to simulate flow for the future period with considerable reliability and the model can give reliable results with projected discharge data for the future period. Model fitness between the daily observed and simulated runoff during the calibration and validation period is presented in Table 6.

Table 6. Statistical Analysis of Streamflow Simulation for Calibration and Validation period

\begin{tabular}{ccccc}
\hline Period & $\mathbf{R}^{\mathbf{2}}$ & NSE & PBIAS & RSR \\
\hline Calibration (2002-2007) & 0.88 & 0.88 & 22.1 & 0.35 \\
Validation (2008-2013) & 0.88 & 0.87 & 22.8 & 0.36 \\
\hline
\end{tabular}

2) Monthly Time Series Simulation for Model Calibration: When the $\mathrm{R}^{2}$ and NSE values improved to 0.88 and 0.88 while decreasing the value of PBIAS and RSR to 22.1 and 0.35 respectively, simulation is seen to be better. According to Figure 6, the time of maximum rainfall intensity was also corresponded to the time of peak flow during the year.

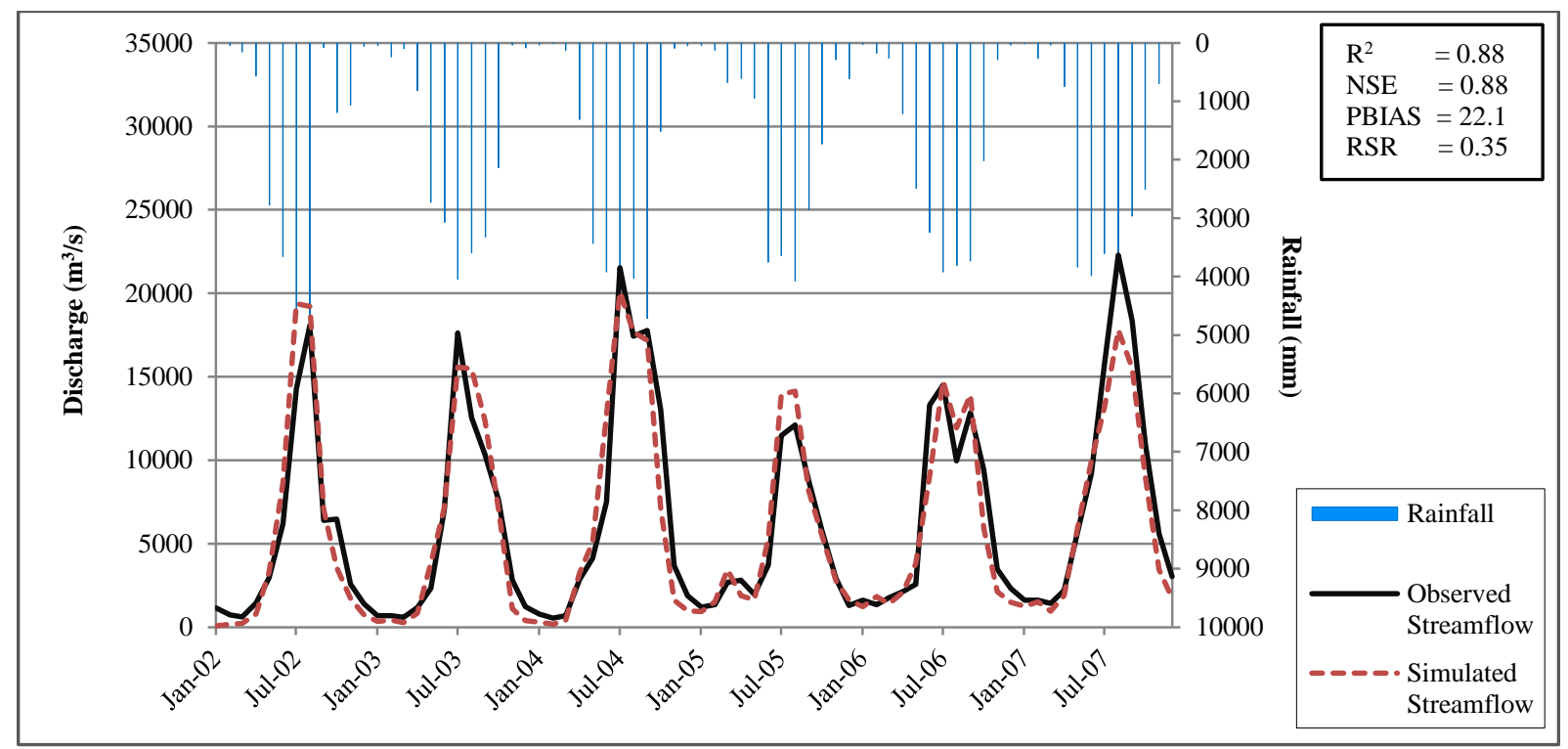

Figure 6. Hydrograph of Monthly Simulated and Observed Flow for Calibration Period (2002-2007, Sagaing Outlet)

3) Monthly Time Series Simulation for Model Validation: The values of statistical indicators: $\mathrm{R}^{2}$, NSE, PBIAS, and RSR are all satisfied with the value of $0.88,0.87,22.8$ and 0.36 . The hydrograph of observed and simulated discharge for the validation period is shown in Figure 7 and better model performance results were attained during monthly time series calibration periods.

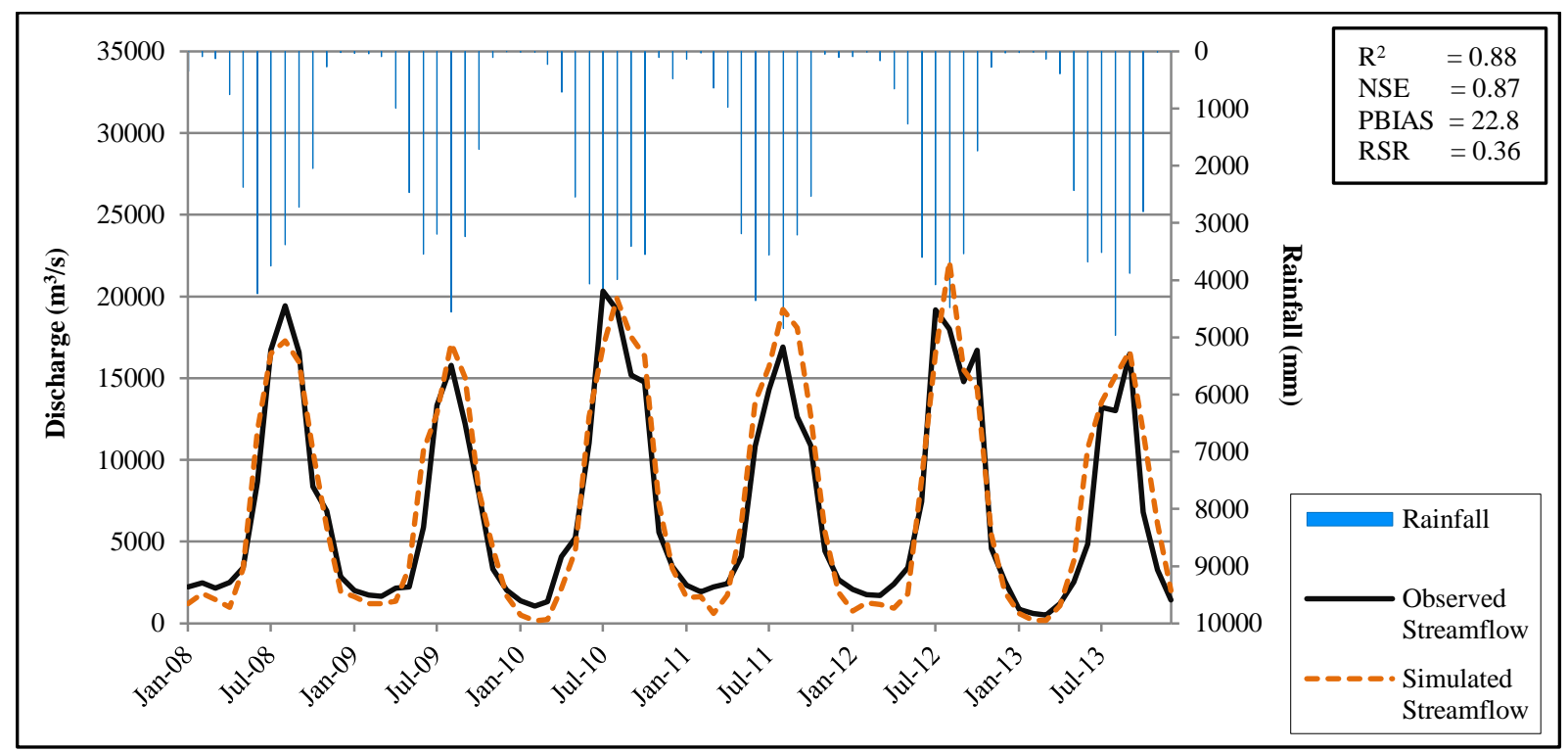

Figure 7. Hydrograph of Monthly Simulated and Observed Flow for Validation Period (2008-2013, Sagaing Outlet) 
All the statistical parameters are satisfactory at both calibration and validation period. $\mathrm{R}^{2}$ with the value of 0.88 also indicates good agreement of the simulated flows with the observed flows during calibration and validation period. NSE values are 0.88 and 0.87 for the calibration and validation period, respectively. The monthly PBIAS values are within the limitations indicating in the value of $22.1 \%$ in calibration and $22.8 \%$ in validation period. RSR also reduces to acceptable limit and all these values indicate that the simulated and observed discharge has a reasonable agreement and the model performance is acceptable.

\subsection{Changes in Average Annual and Seasonal Streamflow at Sagaing Station}

The same values of calibrated SWAT model parameters are applied to evaluate the future climate impact simulations on water resources analysis. The bias-corrected future climate parameters such as precipitation, maximum and minimum temperature obtained from the selection suitable climate models for each station in the study area are used as input climate data for the analysis of hydrological changes under future climate. To evaluate the impact of climate change on the hydrology of the Upper Ayeyarwady river basin, future hydrological projections divided into three-time horizons Near Future (2021-2045), Future (2046-2070) and Far Future (2071-2095) were compared with their baseline average discharge (1991-2015). And then, analysis of future streamflow at Sagaing Outlet is performed under RCP2.6, RCP4.5, and RCP8.5 climate scenarios. The results of average annual and seasonal change (\%) in the basin relative to the base period are shown in Figure 8. According to this figure, seasonal streamflow shows a decreasing trend in all scenarios and periods of the near future, future and far future. But the decrease rate in summer is higher than in the other two seasons. The future average seasonal streamflow shows a definite decrease ranging from $12.9 \%$ to $84.5 \%$ will be lower than the current conditions in the summer season. Average seasonal streamflow will also decrease ranging from $2.8 \%$ to $15.9 \%$ in the rainy season and from $10.6 \%$ to $14.6 \%$ in the winter season. A slight increment of about $13.6 \%$ occurs under RCP2.6 in the far future for winter. There is still clear agreement that the projected annual streamflow during near future, future and far future will be $6.1 \%$ to $30.9 \%$ lower than observed annual streamflow amounts as compared to the observed annual streamflow. About 1.3\% increment occurred under RCP2.6 in the far future of annual streamflow projection.

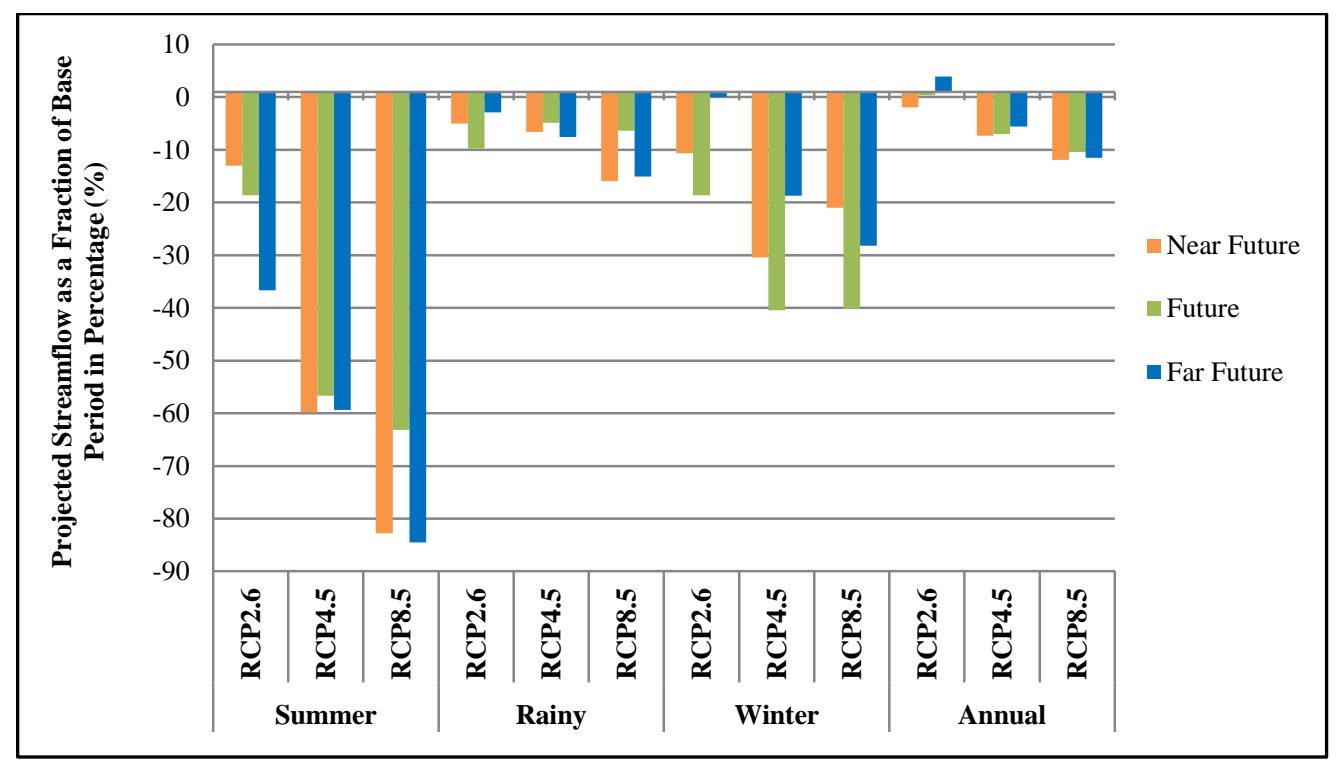

Figure 8. Future Average Annual and Seasonal Streamflow Changes at Sagaing Station

\subsection{Changes in Monthly Streamflow at Sagaing Station}

The comparison between observed and projected average monthly streamflow at the Upper Ayeyarwady river basin for each future period is described in the following Figures. Figure 9 shows the projection of average monthly streamflow for the near future period under three RCP scenarios and figure 10 shows near future average monthly streamflow changes relative to the baseline period. In these figures, the average monthly streamflow is higher than the baseline period from January to May for all RCP scenarios, June for RCP8.5, and October to December for RCP 4.5 and RCP 8.5. In near future, slight increase streamflow is observed under RCP 4.5 in June, July, August, and September, under RCP2.6 in June and September, and under RCP8.5 in August and September. For the summer season (15February to 31May) for near future, streamflow projection under all RCP scenarios indicates a decrease projection change in average of $1932.1 \mathrm{~m}^{3} / \mathrm{s}$ under RCP2.6, $1465.11 \mathrm{~m}^{3} / \mathrm{s}$ under RCP4.5, and $845.9 \mathrm{~m}^{3} / \mathrm{s}$ under RCP 8.5 . The average change in streamflow in summer is at the lowest level under RCP8.5 compared with other RCP scenarios. During the rainy season, the highest and lowest streamflow changes are ranging from about $10106.6-16441.5 \mathrm{~m}^{3} / \mathrm{s}$ under RCP 2.6, 9415.6 $15324 \mathrm{~m}^{3} / \mathrm{s}$ under RCP4.5, and $9252.4-16908 \mathrm{~m}^{3} / \mathrm{s}$ under RCP8.5 in near future. 


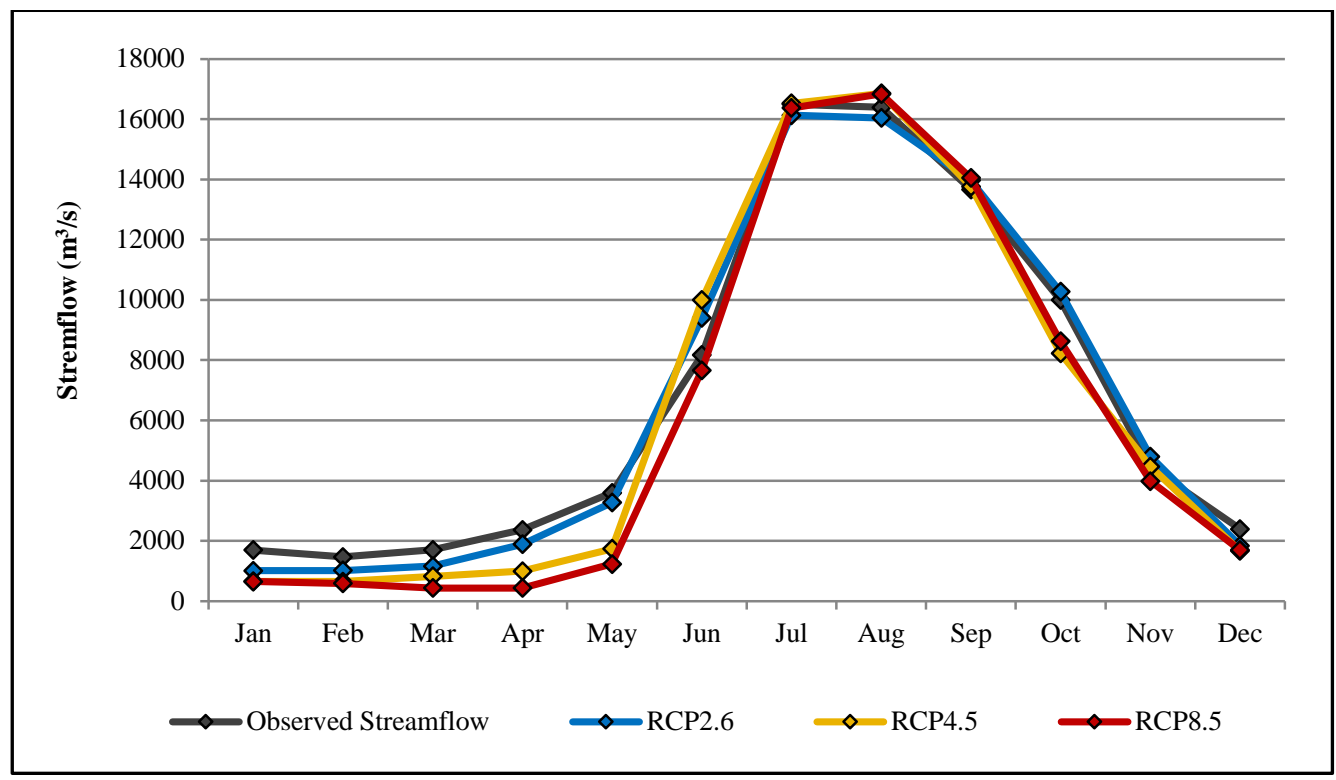

Figure 9. Projected Average Monthly Streamflow in Near Future (2021-2045)

In the future, the average monthly streamflow is higher than the baseline period from January to May for all RCP scenarios, June for RCP8.5, and October to December for RCP 4.5 and RCP 8.5. Simulated streamflow higher than observed streamflow is given for three months: July, August, and September under all RCPs and for June under RCP2.6

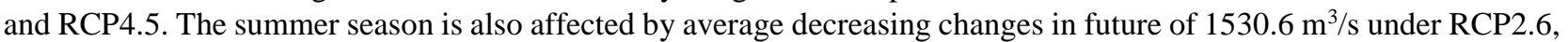
$1213.1 \mathrm{~m}^{3} / \mathrm{s}$ under RCP4.5, and $724 \mathrm{~m}^{3} / \mathrm{s}$ under RCP8.5. The rainy seasonal flow projections under RCP2.6, RCP4.5 and RCP8.5 conditions for future are also ranging from about $10060-16333.9 \mathrm{~m}^{3} / \mathrm{s}, 10680-16889.4 \mathrm{~m}^{3} / \mathrm{s}$, and 9701.3 $-17566 \mathrm{~m}^{3} / \mathrm{s}$, respectively.

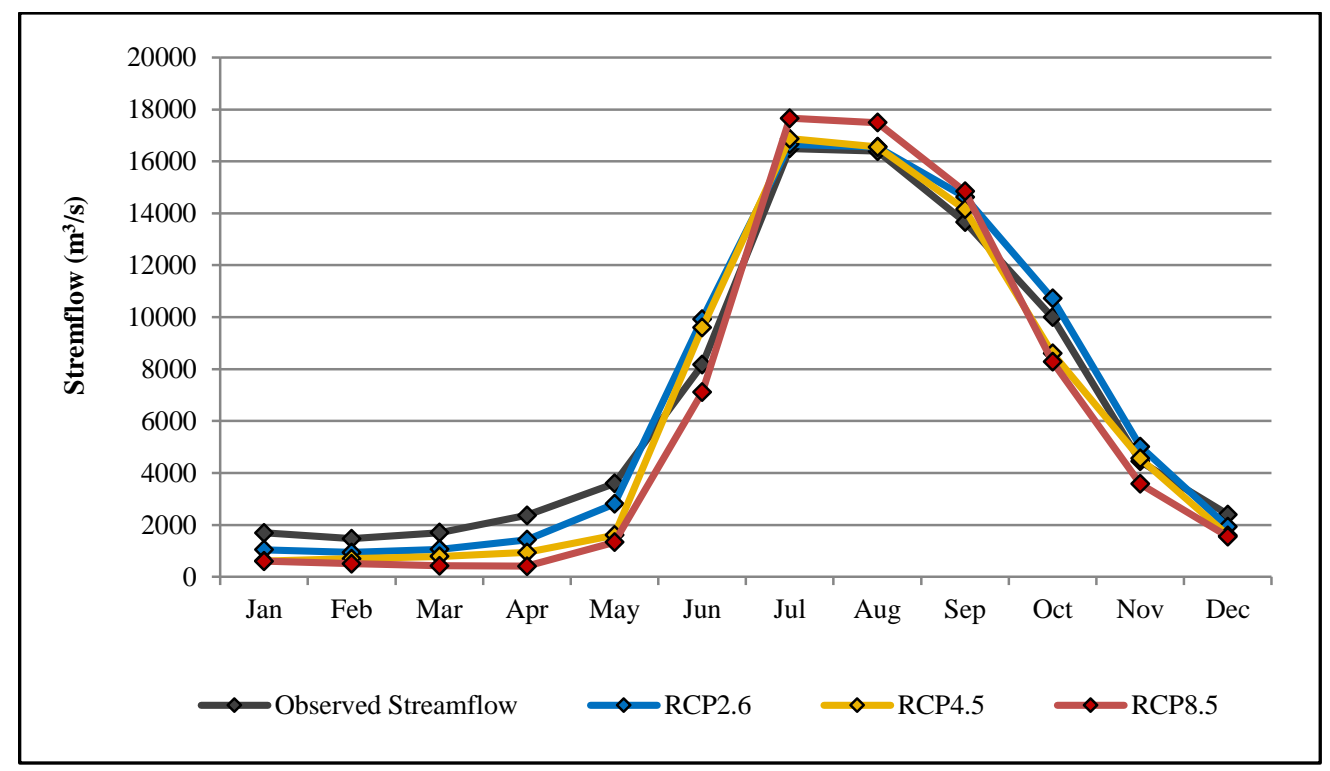

Figure 10. Projected Average Monthly Streamflow in Future (2046-2070)

The projection of average monthly streamflow with respect to the baseline under all RCPs for the future is shown in Figure 11. This figure shows the declining streamflow changes during the summer and winter season (from January to May and from October to December) under all scenarios. In July and August, for the far future period, the simulated flow of RCP8.5 is higher than the flow of RCP2.6 and RCP4.5 after comparing it with the baseline period. Average decrease changes of streamflow projection for summer season in far future is about $992.9 \mathrm{~m}^{3} / \mathrm{s}$ under RCP 2.6, 751.1 $\mathrm{m}^{3} / \mathrm{s}$ under RCP 4.5 , and $448.7 \mathrm{~m}^{3} / \mathrm{s}$ under RCP 8.5 . The rainy seasonal flow projections are also ranging from 10159.5 - $16368.4 \mathrm{~m}^{3} / \mathrm{s}$ under RCP2.6, $9701.3-17066 \mathrm{~m}^{3} / \mathrm{s}$ under RCP4.5, and $8486.3-17918 \mathrm{~m}^{3} / \mathrm{s}$ under RCP8.5. 


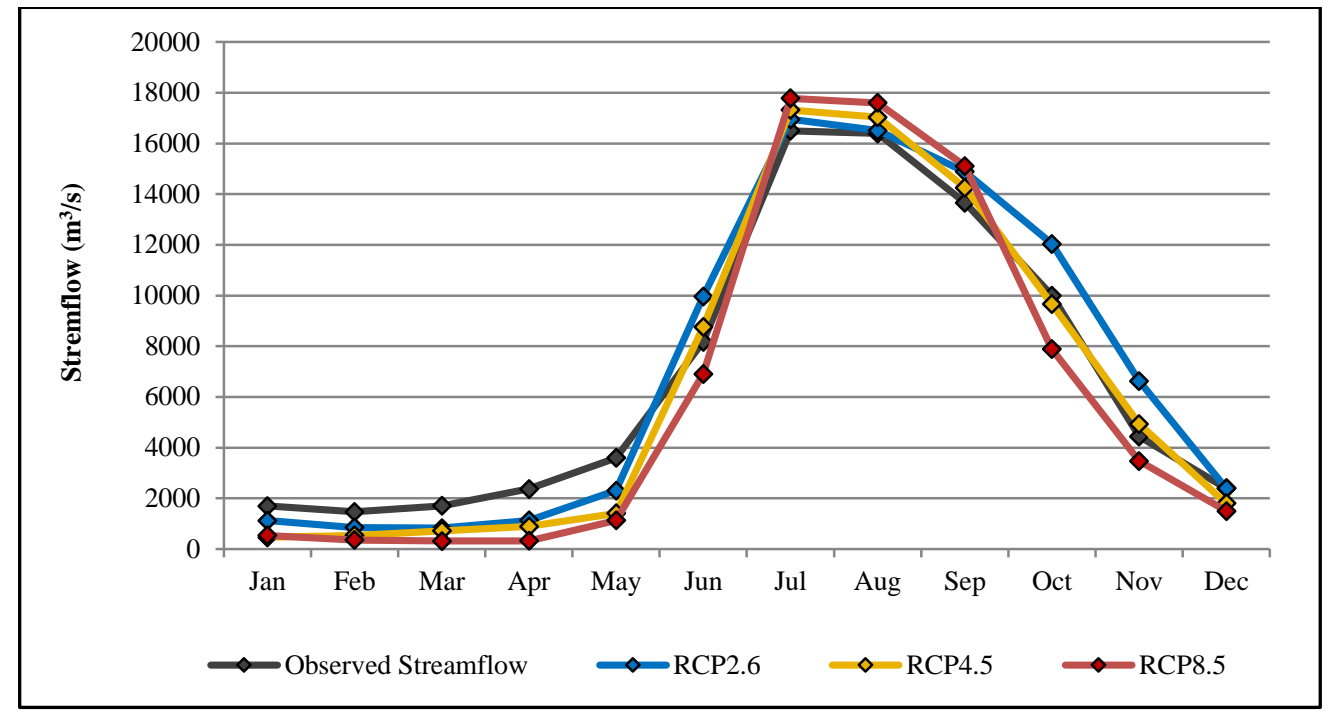

Figure 11. Projected Average Monthly Streamflow in Far Future (2071-2095)

In terms of seasonal scale, it is clear that the projected streamflow will decrease in the summer period. Both increasing and decreasing streamflow are found in the rainy and winter period according to their RCP scenarios.

\subsection{Impact on High and Low Flow of Upper Ayeyarwady River Basin at Sagaing Outlet}

According to the future high flow results shown in Figure 12, projected future streamflow has an increasing trend from RCP2.6 to RCP8.5 from the year 2021 to 2095 indicates severe floods will ever experience in the future. It also means that water-related disasters such as floods, landslides, etc. will be more encountered in RCP4.5 and RCP8.5 conditions than in RCP2.6.

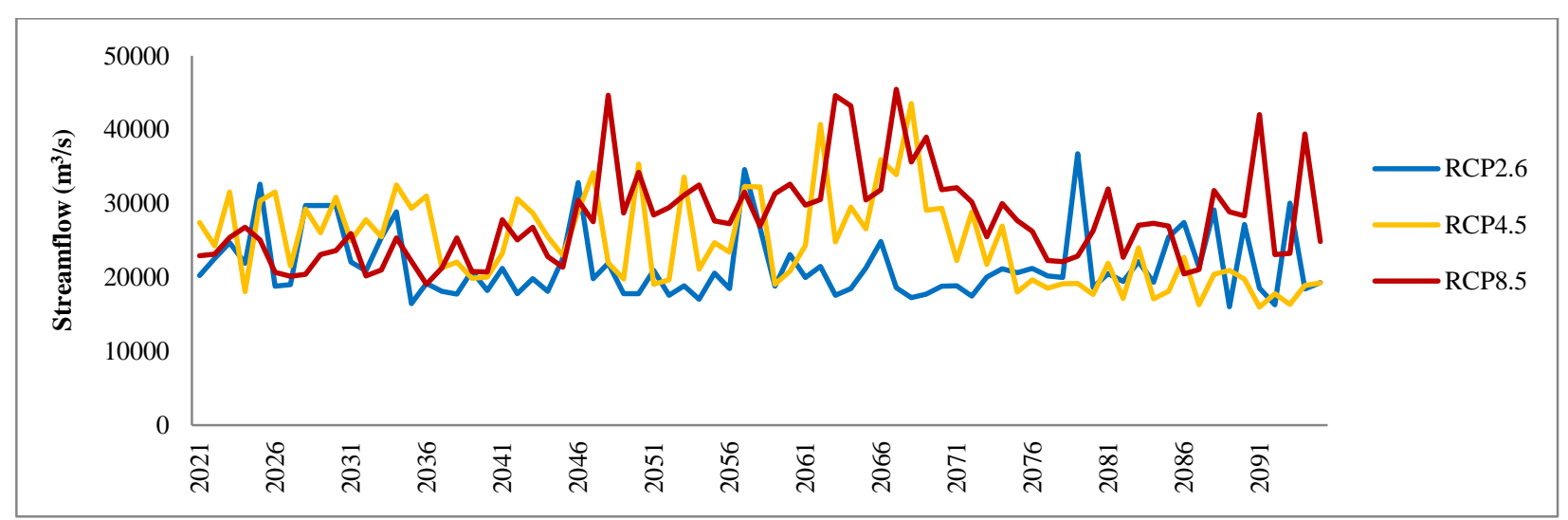

Figure 12. Projected Maximum Discharge in Sagaing Outlet for Wet Season

Figure 13 describes the projected future low flow from the year 2021 to 2095 and it is forecasted as the streamflow will decrease more and more in relation to their future scenarios and that indicates water problem will grow worse in the future.

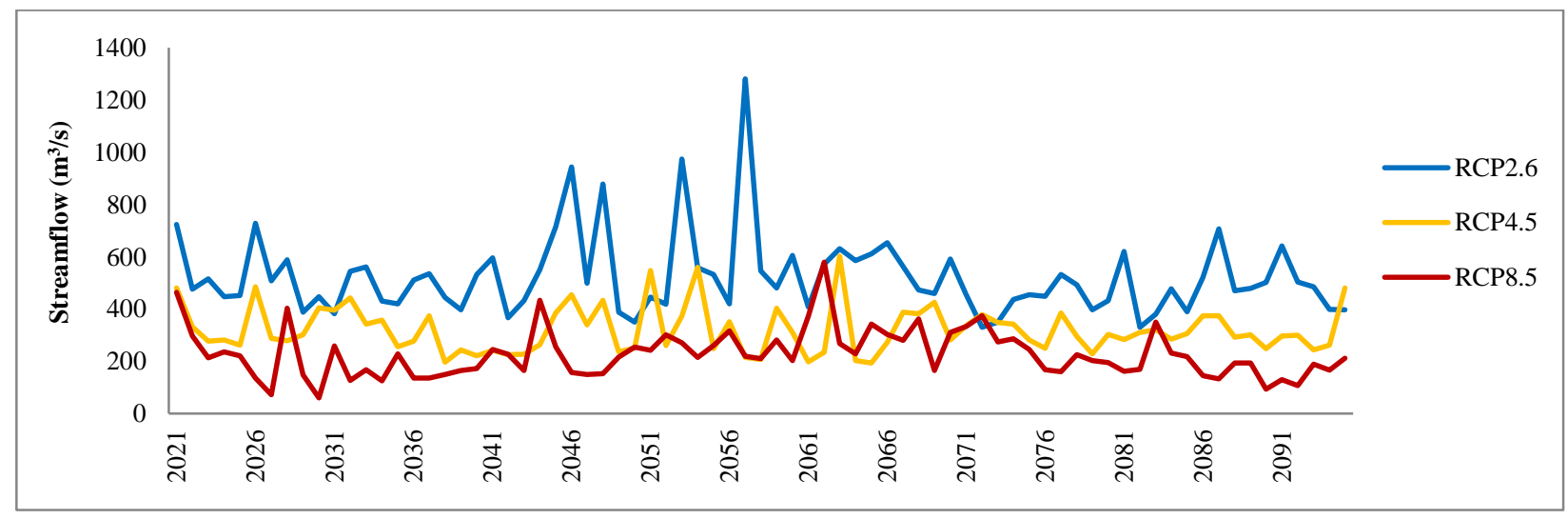

Figure 13. Projected Minimum Discharge in Sagaing Outlet for Dry Season 
The relative changes of high and low flow of Upper Ayeyarwady River Basin concerning the baseline period (19912015 ) are presented in Figure 14. The projected high flow indicated that the flow will be increased ranging from $3.1 \%$ to $12.7 \%$ under RCP2.6, $2.8 \%$ to $33.5 \%$ under RCP4.5, and $25.7 \%$ to $28.9 \%$ under RCP8.5. The range of changes in low flow is $5.1 \%$ to $13 \%$ under RCP2.6, $37.1 \%$ to $48.3 \%$ under RCP4.5, and $64.2 \%$ to $74.2 \%$ under RCP8.5. Here, changes percentage in low flow is greater than that of high flow. Both increasing rates in high flow and decreasing rate in low flow are more serious under RCP8.5 than RCP2.6 and RCP4.5.

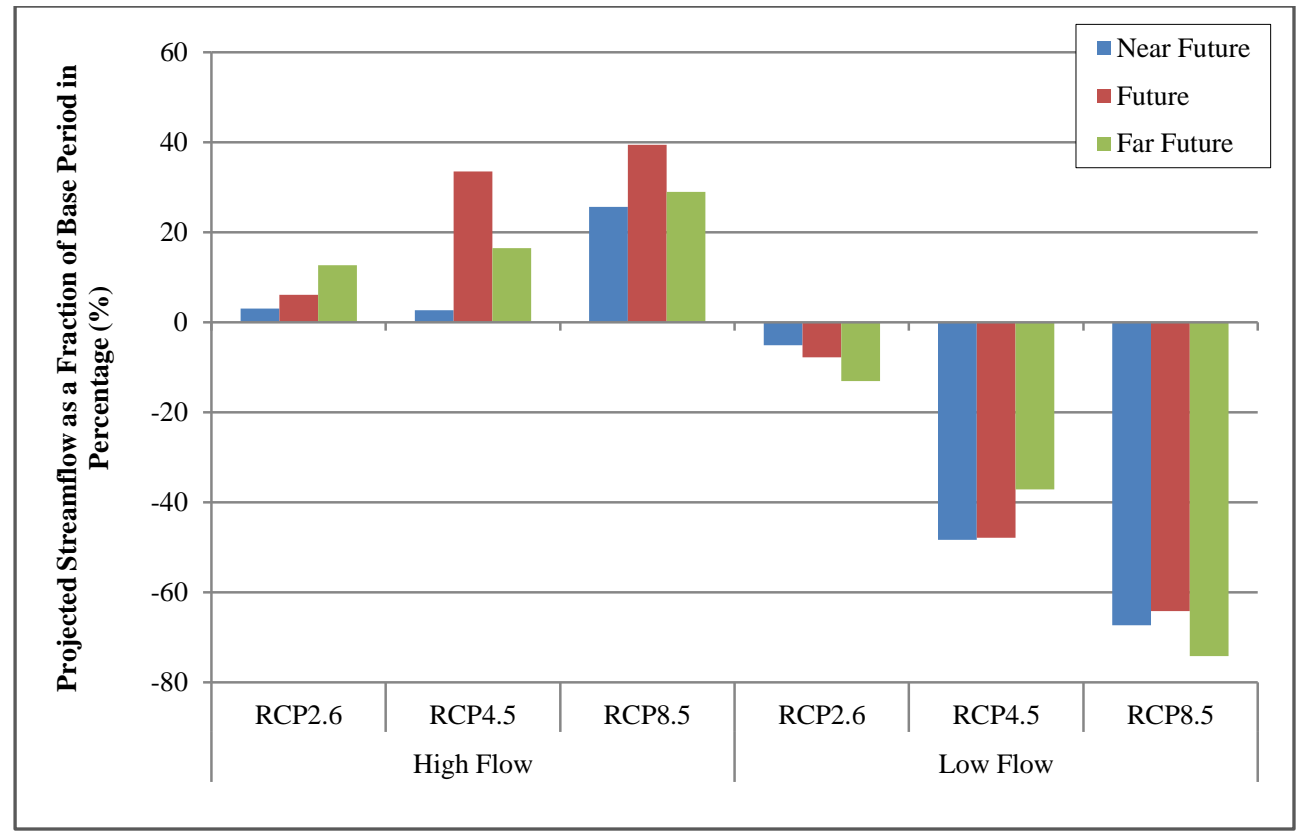

Figure 14. Projected Changes Percentage in High and Low Flow of Upper Ayeyarwady River Basin

\section{Conclusion}

The assessment of climate change impacts on hydrology is related to the climate change scenarios and hydrological model. Runoff projection with GCMs, emission scenarios and future periods is investigated as well. Changes of Upper Ayeyarwaddy river flow during 2020-2100 were predicted by using projected precipitation and temperature related to outputs of selected best climate models form 10 GCMs under RCP2.6, RCP4.5, and RCP8.5 scenarios. Estimating the impacts of possible future climate change on hydrological behaviour is done by calibration and validation of the SWAT hydrological model by using current climatic inputs, land-use map, and observed river flow. Better model performance results were attained a satisfactory value of $\mathrm{R}^{2}=0.88, \mathrm{NSE}=0.88, \mathrm{PBIAS}=22.1$ and $\mathrm{RSR}=0.35$ during monthly time series calibration period and value of $\mathrm{R}^{2}=0.88, \mathrm{NSE}=0.87$, PBIAS $=22.8$ and $\mathrm{RSR}=0.36$ during validation period. The overall conclusion of this research is that the Upper Ayeyarwady area predicted to encounter excessive precipitation especially in the rainy season and extreme temperature especially in the future summer season. And then, it can also be concluded that river flow followed the rainfall pattern because the river flow is found as the low flow in the dry season and high flow in the wet season. Moreover, changing climate conditions are getting worse with the increased rate of GHG emissions levels in the atmosphere and increasing in frequency and intensity of rainfall lead to floods and increasing in water scarcity and drought. It is found that current Myanmar's climate condition is still below the RCP2.6 level according to the comparison between observed and simulated data and therefore, it is necessary to control and reduce flood potentials in the wet season and the severity of drought in the dry season. But, if the greenhouse gas emissions rate in Myanmar cannot reduce, the level of gas will keep going up and face to reach the RCP4.5 and RCP8.5 conditions. Therefore, stronger efforts and finding ways to reduce and to mitigate carbon dioxide emissions should be undertaken to lower global warming and climate change in the atmosphere.

\section{Acknowledgements}

The author would like to express her sincere gratitude to Dr. Nyan Myint Kyaw, Professor, and Head of Civil Engineering Department of Yangon Technological University, for his valuable management, motivation, and immense knowledge. The author is sincerely thankful to her supervisor Dr. Win Win Zin, Professor, and Dr. Cho Cho Thin Kyi, Associate Professor of the Department of Civil Engineering of Yangon Technological University, for their patient guidance, helpful suggestions, and valuable knowledge and suggestion. The author would like to thank her parents for supporting her spiritually throughout this research and her life. Finally, the author offers her thanks to all persons who pay support, guidance and kind help for this study. 


\section{Conflicts of Interest}

The authors declare no conflict of interest.

\section{References}

[1] Intergovernmental Panel on Climate Change (IPCC), ed. "Near-Term Climate Change: Projections and Predictability." Climate Change 2013 - The Physical Science Basis, Cambridge University Press (2013): 953-1028. doi:10.1017/cbo9781107415324.023.

[2] Intergovernmental Panel on Climate Change (IPCC). "Climate change 2007: Impacts, adaptation and vulnerability." Genebra, Suíça (2001).

[3] Gleick, Peter H., and Elizabeth L. Chalecki. "The Impacts of Climatic Changes for Water Resources of the Colorado and Sacramento-San Joaquin River Basins.” Journal of the American Water Resources Association 35, no. 6 (December 1999): 14291441. doi:10.1111/j.1752-1688.1999.tb04227.x.

[4] Kepner, William G., Darius J. Semmens, Scott D. Bassett, David A. Mouat, and David C. Goodrich. "Scenario Analysis for the San Pedro River, Analyzing Hydrological Consequences of a Future Environment." Environmental Monitoring and Assessment 94, no. 1-3 (2004): 115-127. doi:10.1023/B:EMAS.0000016883.10110.15.

[5] Myanmar Climate Change Alliance. "Myanmar Climate Change Strategy: 2018-2030” (2019). https://doi.org/10.1163/22132996_flg_com_138028

[6] Lai Lai Aung, Ei Ei Zin, Pwint Theingi, Naw Elvera, Phyu Phyu Aung, Thu Thu Han, Yamin Oo, and R.G. Skaland. "Myanmar climate report.” Norwegian Meteorological Institute, No.9, ISSN 2387-4201 (2017).

[7] Groombridge, B., and M. Jenkins. "Freshwater Biodiversity: A Preliminary Global Assessment. Cambridge (United Kingdom): World Conservation Monitoring Centre (WCMC)." (1998).

[8] Khin Moe Kyi. “Farmer Vulnerability Amidst Climate Variability: A case study of Dry Zone of Myanmar.” ICIRD (2012).

[9] Davies. R. "Myanmar - Deadly Floods and Landslides Strike Mohnyin District, Kachin State.” Floodlist (June 2018). Available online: http://floodlist.com/asia/myanmar-floods-landslides-strike-kachin-state-june-2018.

[10] Prudhomme, Christel, Dörte Jakob, and Cecilia Svensson. "Uncertainty and Climate Change Impact on the Flood Regime of Small UK Catchments.” Journal of Hydrology 277, no. 1-2 (June 2003): 1-23. doi:10.1016/s0022-1694(03)00065-9.

[11] Hijioka, Y., Lin, E., Pereira, J.J., Corlett, R.T., Cui, X., Insarov, G.E., Lasco, R.D., Lindgren, E., and Surjan, A. "Impacts, Adaptation, and Vulnerability. Part B: Regional Aspects. Contribution of Working Group II to the Fifth Assessment Report of the Intergovernmental Panel of Climate Change." Cambridge University Press, Cambridge, United Kingdom and New York, NY, USA (January 2015).

[12] Wilby, Robert L., Hany Hassan, and Keisuke Hanaki. "Statistical Downscaling of Hydrometeorological Variables Using General Circulation Model Output.” Journal of Hydrology 205, no. 1-2 (February 1998): 1-19. doi:10.1016/s0022-1694(97)00130-3.

[13] Nakicenovic, N., and Swart, R. "Special report on emission scenarios," Cambridge, UK, p.612, 2000.

[14] Arnold, J. G., R. Srinivasan, R. S. Muttiah, and J. R. Williams. "Large Area Hydrologic Modeling and Assessment Part I: Model Development." Journal of the American Water Resources Association 34, no. 1 (February 1998): 73-89. doi:10.1111/j.17521688.1998.tb05961.x.

[15] Su Wai Aung, and Nilar Aye. "Sediment Yield Simulation in Upper Ayeyarwady Basin.” American Scientific Research Journal for Engineering, Technology, and Sciences (ASRJETS), Volume 27, No 1 (January): 405-418 (January 2007).

[16] Helfer, Fernanda, Charles Lemckert, and Hong Zhang. "Impacts of Climate Change on Temperature and Evaporation from a Large Reservoir in Australia.” Journal of Hydrology 475 (December 2012): 365-378. doi:10.1016/j.jhydrol.2012.10.008.

[17] Van Vuuren, Detlef P., Michel G. J. den Elzen, Paul L. Lucas, Bas Eickhout, Bart J. Strengers, Bas van Ruijven, Steven Wonink, and Roy van Houdt. "Stabilizing Greenhouse Gas Concentrations at Low Levels: An Assessment of Reduction Strategies and Costs." Climatic Change 81, no. 2 (February 13, 2007): 119-159. doi:10.1007/s10584-006-9172-9.

[18] Riahi, Keywan, Arnulf Grübler, and Nebojsa Nakicenovic. "Scenarios of Long-Term Socio-Economic and Environmental Development Under Climate Stabilization.” Technological Forecasting and Social Change 74, no. 7 (September 2007): 887935. doi:10.1016/j.techfore.2006.05.026.

[19] Almeida, Rafael A., Silvio B. Pereira, and Daniel B. F. Pinto. "Calibration and Validation of the Swat Hydrological Model for the Mucuri River Basin.” Engenharia Agrícola 38, no. 1 (January 2018): 55-63. doi:10.1590/1809-4430-eng.agric.v38n1p55$63 / 2018$. 
[20] Arnold, J., Williams, J., Srinivasan, R., and King, K. "SWAT - soil and water assessment tool - documentation and user's manual.” USDA-ARS, Temple, Texas, 1996. Available online: http://swat.tamu.edu/documentation/.

[21] K. R. Douglas-Mankin, R. Srinivasan, and J. G. Arnold. "Soil and Water Assessment Tool (SWAT) Model: Current Developments and Applications.” Transactions of the ASABE 53, no. 5 (2010): 1423-1431. doi:10.13031/2013.34915.

[22] Mengistu, Achamyeleh G., Leon D. van Rensburg, and Yali E. Woyessa. "Techniques for Calibration and Validation of SWAT Model in Data Scarce Arid and Semi-Arid Catchments in South Africa." Journal of Hydrology: Regional Studies 25 (October 2019): 100621. doi:10.1016/j.ejrh.2019.100621.

[23] Vervoort, W. “Course Notes Advanced SWAT: Calibrating using SWAT-CUP.” University of Sydney, IRI, INIA (2017).

[24] Tejaswini, V., and K.K. Sathian. "Calibration and Validation of Swat Model for Kunthipuzha Basin Using SUFI-2 Algorithm." International Journal of Current Microbiology and Applied Sciences 7, no. 1 (January 10, 2018): $2162-2172$. doi:10.20546/ijcmas.2018.701.260.

[25] Nash, J.E., and J.V. Sutcliffe. “River Flow Forecasting through Conceptual Models Part I — A Discussion of Principles.” Journal of Hydrology 10, no. 3 (April 1970): 282-290. doi:10.1016/0022-1694(70)90255-6.

[26] Oo, Han Thi, Win Win Zin, and Cho Cho Thin Kyi. “Assessment of Future Climate Change Projections Using Multiple Global Climate Models.” Civil Engineering Journal 5, no. 10 (October 7, 2019): 2152-2166. doi:10.28991/cej-2019-03091401.

[27] Setegn, Shimelis G., Ragahavan Srinivasan, Assefa M. Melesse, and Bijan Dargahi. "SWAT Model Application and Prediction Uncertainty Analysis in the Lake Tana Basin, Ethiopia.” Hydrological Processes 24 (2009): 357-367. doi:10.1002/hyp.7457.

[28] Arnold, J.G., and P.M. Allen. “Estimating Hydrologic Budgets for Three Illinois Watersheds.” Journal of Hydrology 176, no. 1-4 (March 1996): 57-77. doi:10.1016/0022-1694(95)02782-3.

[29] Neitsch, S.L., Arnold, J.G., Kiniry, J.R., and Williams, J.R. "Soil and Water Assessment Tool - Theoretical Documentation." Version 2009 (2011). 